\title{
Rethinking the Legal Form and Principles of a New
}

\section{Climate Agreement}

Geir Ulfstein and Christina Voigt

\begin{abstract}
The Durban Platform for Enhanced Action (ADP) provided a mandate to negotiate a new climate agreement by 2015, entering into force from 2020. This chapter examines the legal form and principles of a new agreement. It is argued that the ADP allows states to choose between distinctive options, including the adoption of a new protocol, amendment to the UNFCCC, or a combination including decisions by the Conference of the Parties (COP). The legal form of each of the elements of the agreement must also be assessed. Finally, it is necessary to overcome the binary distinction between the commitments of developed and developing states, and establish a more differentiated and dynamic architecture.
\end{abstract}

\section{Introduction}

In 2011 it was agreed to launch a new Ad hoc Working Group on the Durban Platform for Enhanced Action (ADP) with a mandate 'to develop a protocol, another legal instrument or an agreed outcome with legal force under the Convention applicable to all Parties.’ The new negotiating process, which began in May 2012, is scheduled to end by 2015. The outcome should come into effect and be implemented from 2020 onwards. However, while the door is pushed open for formal discussion on questions of legal form, the choice of form is far from 
settled. The formulation in the ADP decision from Durban is marked by constructive ambiguity and requires further interpretation.

The negotiations of the new climate agreement are also marked by confrontations about its substantive content, not least about how the principle of 'common, but differentiated responsibilities and respective capabilities' should be incorporated in the future agreement. The UNFCCC and the Kyoto Protocol are based on a clear distinction between developed and developing states (Annex I and non-Annex I states). But the basis for this distinction is increasingly becoming blurred by changing economic realities and steeper greenhouse gas emission trends in advanced economies. Accordingly, there is a need to rethink how differentiation in responsibilities should be reflected in a new climate agreement.

Furthermore, the connection between the legal form and the substantive content should be examined. The Durban Platform commits states to negotiate an agreement with a legal status. But this does not necessarily mean that the elements of such an agreement need to be legally binding. It is therefore of interest to discuss which of the elements that should be of a legally binding character, including whether differentiations between states may include the binding nature of their commitments.

This chapter begins with a discussion of the interpretation of the terminology in the Durban Platform on the legal character of a climate agreement. In the next section we deal with the benefits of a legally binding agreement, with a particular focus on the binding character of the different elements of the agreement. Then, we examine different approaches to differentiation between states in the agreement. Finally, we draw some conclusions about the substantive content and legal form of a future climate agreement. 


\section{The Durban Platform of Enhanced Action (ADP) ${ }^{1}$}

Discussions on legal form of a new agreement have weighed on the UNFCCC negotiation process for several years. The 2007 Bali Action Plan² set up the Ad-Hoc Working Group on Long-term Cooperative Action (AWG-LCA) with the purpose of reaching an 'agreed outcome' on long-term cooperative action on climate change in 2009. The term 'agreed outcome', however, does not provide clarity on the legal form or character of the outcome this process should produce, nor did the Bali decision contain a clear mandate to negotiate the legal character of such outcome. Since the Bali Action Plan, many Parties have repeatedly expressed their view that such outcome needs to be of legally binding character. Several Parties submitted proposals for various legally binding instruments under FCCC Article 17. These included different types of protocols from Australia, ${ }^{3}$ Japan, ${ }^{4}$ Grenada ${ }^{5}$, Tuvalu, ${ }^{6}$ and Costa Rica $^{7}$ and an Implementing Agreement from the United States. ${ }^{8}$

Decision 1/CP.17 limits the choice of legal form of a new climate agreement to three options: a protocol, another legal instrument or an agreed outcome with legal force under the

\footnotetext{
${ }^{1}$ The following paragraphs draw upon: Christina Voigt (2012): The Legal Form of the Durban Platform Agreement: Seven Reasons for a Protocol, 15:3 Ethics, Policy \& Environment, 276-282.

2 Decision 2/CP.13.

${ }^{3}$ Draft protocol to the Convention prepared by the Government of Australia for adoption at the fifteenth session of the Conference of the Parties, FCCC/CP/2009/5 (6 June 2009).

${ }^{4}$ Draft protocol to the Convention prepared by the Government of Japan for adoption at the fifteenth session of the Conference of the Parties, FCCC/CP/2009/3 (13 May 2009).

${ }^{5}$ Proposed protocol to the Convention submitted by Grenada for adoption at the sixteenth session of the Conference of the Parties, FCCC/CP/2010/3 (2 June 2010).

${ }^{6}$ Draft protocol to the Convention presented by the Government of Tuvalu under Article 17 of the Convention, FCCC/CP/2009/4 (5 June 2009).

${ }^{7}$ Draft protocol to the Convention prepared by the Government of Costa Rica for adoption at the fifteenth session of the Conference of the Parties, FCCC/CP/2009/6 (8 June 2009).

${ }^{8}$ Draft implementing agreement under the Convention prepared by the Government of the United States of America for adoption at the fifteenth session of the Conference of the Parties, Note by the secretariat, FCCC/CP/2009/7 (6 June 2009).
} 
convention. Except for setting up these alternatives, the decision is silent on the legal character of that agreement, notably in the absence of the term "legally-binding”.

A preliminary question is whether the qualifier "under the Convention” shall apply to all three options. ${ }^{9}$ If answered in the affirmative, the qualifier excludes tracks separate from the convention, such as purely domestic or regional arrangements and laws.

Option 1 then reads to be "a protocol... under the Convention" and pertains to a protocol according to Article 17 UNFCCC. Option 2 is less straightforward. It would read as “another legal instrument ... under the Convention”. Legal instruments under the Convention could refer to any of the legally binding instruments which the Conference of the Parties (COP) has the competence to adopt. These are - in addition to protocols - amendments (Article 15), annexes (Article 16) and amendments to annexes (Article 16). However, the COP may also adopt decisions. The majority view is that COP decisions are generally political in character and not legally binding. Legal bindingness may, however, be achieved in the exceptional circumstance that an explicit mandate by the treaty that establishes the COP (the Convention) empowers the COP to "regulate" or "legislate" through decisions. The Convention does not contain an explicit 'regulatory mandate' for the COP. ${ }^{10}$ This does not necessarily mean that COP decisions are devoid of legal effects. The decisions may have significance for the interpretation of substantive obligations of the states parties. They may also be binding at the internal level, for example decisions about the establishment of

\footnotetext{
${ }^{9}$ The issue of the legal form of a new agreement 'under the convention' is separate from the question whether all principles and provisions of the convention should equally apply to that agreement. The latter question is not discussed here.

${ }^{10}$ The UNFCCC only empowers the COP to "make, within its mandate, the decisions necessary to promote the effective implementation of the Convention" and to "exercise such other functions as are required for the achievement of the objective of the Convention”. Article 7.2 UNFCCC.
} 
subsidiary bodies or the adoption of rules of procedure. ${ }^{11}$ In the absence of an amendment to the Convention or a new protocol authorizing the COP to adopt binding decisions it is, however, difficult to see COP decisions as a relevant 'legal instrument(s)'. ${ }^{12}$

The third option is the least clear. The formulation "an agreed outcome with legal force under the convention” uses language which does not appear in the Convention. It has been suggested that this option "seems to be designed to allow room for the negotiations to end with an outcome that doesn't take the form of the legal instruments expressively contemplated in the Convention, and yet is still 'under the Convention'.”13

The term 'agreed outcome with legal force' is considered to be a more ambiguous option than the first two. This option conceivably gives more room for maneuver in negotiating the new climate agreement as it does not limit the result to one instrument. Rather, there could be a package of instruments including perhaps several COP decisions as well as a protocol/-s.

The ambiguity in the formulation 'agreed outcome with legal force' raises the same question as pertains to 'legal instrument', namely whether a non-binding COP decision could qualify as such 'outcome'. An 'agreed outcome with legal force' may well include COP decisions, but not as the sole result. Rather, one (or more) protocol(s) would need to be part of that package. The 'agreed outcome' could, for example, consist of (i) a protocol which in turn

\footnotetext{
${ }^{11}$ Robin Churchill and Geir Ulfstein, Autonomous Institutional Arrangements in Multilateral Environmental Agreements: A Little noticed Phenomenon in International Law, American Journal of International Law, Vol. 94, No. 4, October 2000, 623-660, 634.

${ }^{12}$ As mentioned above, many states made clear the need for a legally binding agreement. As one climate expert noted: "Given the gathering momentum towards a legally binding instrument in the lead-up to the Durban Climate Conference, it would be safe to assume that the majority of countries that negotiated the Durban Platform, however, did not intend this [to consider COP decisions 'legal instruments'] to be the case." See Lavanja Rajamani, The Durban platform for enhanced action and the future of the climate regime, 61:2 International Comparative Law Quarterly, 2012, 506.

${ }^{13}$ J Werksman, Q\&A: The Legal Aspects of the Durban Platform Text, WRI Insights, 14 December, 2011.
} 
empowers the COP or its governing body to "regulate through decisions" similar to article 17 of the Kyoto Protocol which instructs the COP to "define the relevant principles, modalities, rules and guidelines, in particular for verification, reporting and accountability for emissions trading”, (ii) the decisions taken under that mandate and (iii) of aspirational decisions with a lesser degree of stringency and specificity.

Meanwhile, the possibility has been contemplated that 'an agreed outcome with legal force’ could also be interpreted as legal instruments embodied in domestic, rather than international law. ${ }^{14}$ Such 'bottom-up' legal construction is reminiscent of an 'implementing agreement' that allows for 'legally binding approaches' based on Parties' municipal law. ${ }^{15}$ This view, however, is difficult to maintain. The qualifying term "under the Convention" limits the range of options to those entailed in that international legal instrument, i.e. protocols, amendments and annexes. The difference to options 1 and 2, which envisage single instruments, lies in the fact that option 3 allows for the combination of a number of different instruments in a 'package solution' as explained above and thereby creates greater flexibility. ${ }^{16}$

Finally, Decision 1/CP.17 instructs the ADP to complete its work no later than 2015 in order to adopt a protocol, another legal instrument or an agreed outcome with legal force at

\footnotetext{
${ }^{14}$ Rajamani, 2012, 507. Daniel Bodansky, The Durban Platform Negotiations: Goal and Options, Harvard Project on Climate Agreements, Viewpoint, June 2012, 3 and Daniel Bodansky, The Durban Platform: Issues and Options for a 2015 Agreement, Center for Climate and Energy Solutions, December 2012.

${ }^{15}$ Rajamani, 2012, 507. See also India's submission to the ADP, where it is noted that "an agreed outcome with legal force' needs not have the legal form of a protocol or a legal instrument; it could be an outcome that derives legal force from municipal or international law.” Indian Submission on ADP Work Plan, FCCC/ADP/2012/Misc.3, 30 April 2012, 33.

${ }^{16}$ Moreover, a solution based on domestic climate laws may not satisfy the requirements of universal applicability required by Decision 1/CP.17. In order to be 'applicable to all Parties', the outcome must adhere to a certain degree of consistency and coherence in form and character, even if not in substance. This element pays respect to the insistence of the US and others on legal symmetry. Universality of application, thus, prevents a solution based on (many different) domestic instruments. This argument is further supported by the need to strengthen "the multilateral, rules-based regime under the Convention" as expressed in the third paragraph of the Preamble to Decision 1/CP.17.
} 
COP 21 and for it to come into effect and be implemented from 2020. COP-decisions do not need to "come into effect”. On the other hand, legally binding instruments such as a protocol, would require certain domestic legislative processes to take place before they can enter into force and come into effect. The time gap of 5 years indicates that there is a difference between 'adoption', ‘coming into effect' and 'implementation' of the new climate agreement. In other words, the time frame indicates the necessity of a lengthy process for the 'evolution' from adoption to implementation, reminiscent of a ratification process of an international agreement. Such procedural time-window would neither be necessary for purely domestic solutions, nor for decisions of the COP. Rather, the generous timeframe provides yet another interpretative argument for the legally binding possibilities under the UNFCCC.

\section{Which elements should be legally binding?}

\subsection{Introduction}

There is no necessary connection between a legally binding instrument and the binding status of each of the elements of such an instrument. While the instrument can be of legally binding nature, its provisions need not be binding. ${ }^{17}$

One example is the emissions reduction commitment in article 4(2) of the UNFCCC. This provision is part of a binding instrument, but is arguably not a legally binding obligation. ${ }^{18}$ Being part of a binding legal instruments means that also this provision is subject to the accepted principles of treaty interpretation, as reflected in articles 31-33 of the Vienna Convention on the Law of Treaties (1969). Furthermore, violation of a binding legal

\footnotetext{
${ }^{17}$ D Bodansky, The Durban Platform: Issues and Options for a 2015 Agreement (Center for Climate and Energy Solutions. Available at SSRN: http://ssrn.com/abstract=2270336,Published, 2012), 3.

${ }^{18}$ D Bodansky, 'The United Nations Framework Convention on Climate Change: A Commentary, 'Yale Journal of International Law 18, 1993, 451-558, 516.
} 
instrument may entail stronger political condemnation. i.e. a heightened 'shaming factor'. Elements of a legally binding instrument may also more likely be implemented in national legislation. ${ }^{19}$ But its breach will have no legal consequences at the international level.

In the following a functional approach will be applied. It will be asked which elements of a legally binding instrument should, in light of the international legal consequences, have a legally binding character. But it will also be examined whether such elements should be contained in the legal instrument itself, or be delegated to subsequent decisions by the COP.

\subsection{The legal character of different elements}

The legal consequences of including elements of a binding character may be different, dependent of the character of the rule. For example, binding procedural rules may delegate powers to the COP to adopt legally binding - as opposed to political ('soft law') - decisions. While legally binding substantive obligations, such as emissions reduction commitments, may, in cases of violation, have legal consequences as defined in the relevant instrument, possibly including sanctions. They may also entitle other states parties to take legal action, such as countermeasures, under general international law. The different legal consequences will be discussed in relation to the pertinent elements of the legal instrument.

\subsubsection{Objectives and principles}

The objectives and principles for cooperation may be contained either in the preamble or in the articles - the operative provisions - of a legal instrument. While the preambular provisions are not binding as such, the operative provisions are at the outset binding.

\footnotetext{
${ }^{19}$ D Bodansky, The Art and Craft of International Environmental Law (Harvard University Press, 2010), 179.
} 
However, the objectives and principles are by nature not immediately operational they are meant to serve as a background for the operative provisions. They may be used in the interpretation of the operative provisions and serve as guidance in establishing the powers of the COP and other institutional organs. Decisions taken by the COP and other organs may even be considered invalid cooperation (ultra vires) if they contradict the objectives and principles for the cooperation. Whether such objectives and principles are contained in the preamble or in the operative provisions will not necessarily make much legal difference. But their inclusion in the operative provisions may give them a stronger political status.

\subsubsection{Emissions reductions and limitations}

Emissions reductions and limitations of greenhouse gases are at the core of a new climate agreement. The need for binding legal obligations depends on their strictness. But if the $2^{\circ} \mathrm{C}$ (or even $1,5^{\circ} \mathrm{C}$ ) goal shall be reached, strict obligations would be required. In such case, the burdens on states would be significant and the temptation to circumvent - acting as a 'free rider' - would increase correspondingly. Both the need for national implementation and the 'shaming factor' in case of violation would speak in favour of internationally binding emissions reductions and limitations. But are legally binding obligations desirable due to the legal consequences of violations?

In principle, it would not be necessary to have legally binding emissions reductions and limitations in order to impose binding consequences, such as sanctions, under a climate agreement (see 3.2.5. below). Such legally binding consequences can be established on any factual or legal basis as defined by the states parties in the agreement. But states would hardly impose legally binding consequences for violations of political (soft law) commitments. Furthermore, the legal status may be of importance for allocation of benefits under the climate 
agreement, whether it pertains to rights to trade in quotas (see 3.2.3. below), receipt of economic or technological incentives (see 3.2.4. below) or representation by the relevant state party on elected subsidiary organs.

The use of legally binding emissions reductions and limitations would also allow states to apply general international law in the form of countermeasures and state responsibility against states that do not respect their obligations. Moreover, they may take them to available international courts outside the climate regime, such as the International Court of Justice. While other states usually will be reluctant to take such actions, they should not be ruled out. The whaling case brought by Australia and New Zealand against Japan is an example of states taking court action to enforce a multilateral regime for living resources. ${ }^{20}$

The use of legally binding commitments may also be of significance with respect to other international obligations. The international legal system is increasingly fragmented in terms of diverse regulations in different legal regime, such as trade, human rights and the environment. It may be of importance that the commitments under the climate regime are legally binding in order to prevail in relation to other treaties, such as the international trade regime. $^{21}$

\subsubsection{Trade in emission quotas and other flexibility measures}

A new climate agreement may contain different kinds of 'flexibility mechanisms', from trading in emissions quotas to, say, different forms of credits for investment in environmentfriendly technologies in other states, reforestation or reduced emissions from the forest or

\footnotetext{
${ }^{20}$ ICJ, Whaling in the Antarctic (Australia v. Japan) Application (2010), Application instituting proceedings 31 May 2010.

${ }^{21} \mathrm{~J}$ Werksman, 'Compliance and the Use of Trade Measures' in J Brunnée, M Doelle and L Rajamani (eds), Promoting Compliance in an Evolving Climate Regime (CUP, 2012) 262-286
} 
other sectors. Such measures may need a legally binding form in order to ensure effective transactions between the involved states. But a legally binding form is also essential for the connection with substantive obligations concerning emissions reductions and limitations. It is difficult to imagine that states should be credited with such transactions in relation to legally binding emissions reductions and limitations unless also the transactions have a binding legal basis.

\subsubsection{Financial transfer and transfer of technology}

Massive economic and technological support is necessary if the $2^{\circ} \mathrm{C}$ goal (or the $1,5^{\circ} \mathrm{C}$ goal) shall be reached. Financial commitments and transfer of technology by developed states would be part of a package deal.

Such arrangements may take the form of being conditions for implementation of commitments by developing states, as is arguably the case of Article 4.7 UNFCCC. $^{22}$ This would mean that non-fulfilment of the commitments would have legal consequences in the form of suspension of the substantive obligations by developing states. But, first, there may be a need to strengthen the obligations of the developed states through establishing them as unqualified legal obligations, i.e. not only as having the consequence of suspending the obligations of developing states. Furthermore, a legally binding status may be desirable in order to apply legal consequences in cases of violations (see next subsection).

\subsubsection{Non-compliance procedures, including incentives and sanctions}

The legal status of the enforcement measures adopted by the Compliance Committee of the Kyoto Protocol has been disputed. Article 18 of the Protocol establishes that 'any procedures

\footnotetext{
${ }^{22}$ L Rajamani, 'Developing Countries and Compliance in the Climate Regime', ibid, 383.
} 
and mechanisms under this Article entailing binding consequences shall be adopted by means of amendment to this Protocol'. It may thus be argued that none of the consequences adopted by the Committee are binding in the absence of such amendment. ${ }^{23}$

Incentives should obviously be part of a compliance regime. But it would generally seem that stricter commitments would require use of binding legal sanctions as a means to prevent 'free riders'. ${ }^{24}$

The need for legally binding consequences should, however, be assessed in relation to the character of the substantive commitments and of the relevant consequences. For example, it may be asked whether legally binding sanctions should be applied both in relation to violations of substantive obligations and to commitments to provide financial and technological resources. Furthermore, the consequences may be diverse, spanning from a duty to provide a plan on how to bring about compliance to the imposition of financial penalties. The decisive criterion for establishing legally binding consequences should be the need for establishing the sanctions as a separate legal obligation on the relevant states - in addition to the obligations taken on as part of the climate agreement as such.

It should also be mentioned that a competence to adopt legally binding consequences, including sanctions, may have repercussions on the institutional features and procedures of the organs dealing with such issues. First, it should be assured that such organs are credible in terms of assessing both relevant facts and legal commitments. Moreover, the imposition of legally binding consequences should only occur if relevant due process guarantees are

\footnotetext{
${ }^{23}$ G Ulfstein and J Werksman, 'The Kyoto Compliance System: Towards Hard Enforcement' in OS Stokke, J Hovi and G Ulfstein (eds), Implementing the Climate Regime. International Compliance (Earthscan, 2005) , 5758.

${ }^{24}$ D Bodansky, The Art and Craft of International Environmental Law, 236-237.
} 
respected. This may speak in favour of also establishing the organs and their procedures in a legally binding form.

\subsection{Regulations in the agreement vs delegation to the COP}

The establishment of an institutional framework in the form of a COP and possible other organs is key to ensuring a dynamic cooperation and developing the substantive commitments over time - possible all the way to 2050. The Marrakesh Accords is a good example of widereaching decision-making by the COP serving as the meting of the Parties (CMP).

It is necessary to balance which substantive obligations should be contained in the agreement itself and what could be delegated to decisions by the COP. But to the extent that binding legal regulations through COP decisions are needed, the delegation of powers to the COP must be contained in legal provisions in the agreement.

The procedures for decision-making could be left to subsequent adoption by the COP as Rules of Procedure. But such delegation to the COP may, in the absence of consensus, prevent their adoption - as we have seen under the UNFCCC. ${ }^{25}$ It might also be that a more sophisticated system for decision-making should be adopted as part of a climate agreement. Different procedures could be developed for different kinds of decisions. For example, new substantive commitments could require consensus (but not formal amendment and a ratification procedure). Other decisions, e.g. on trading and other flexibility mechanisms, could require forms of qualified majority. This could be combined with systems of weighted voting. The Enforcement Branch of the Kyoto Protocol’s Compliance Committee provides an example by its membership from Annex I and non-Annex I countries, regional representation

\footnotetext{
${ }^{25}$ In the absence of formally adopted rules of procedure, the Climate Change Convention applies draft rules contained in UN Doc. FCCC/CP/1996/2. Draft Rule 42 on majority voting, however, is not applied. See Report of the Conference of the Parties on Its Fifth Session, UN Doc. FCCC/CP/1999/6, paragraph 14.
} 
as well as Small Island Developing States (SIDS), and its requirement of three-quarters majority, including a majority among both Annex I and non-Annex I countries..

In short, a future climate agreement raises not only the question about its legal form, but also the legally binding character of its elements. Furthermore, the consequences of violations of such binding elements must be determined. Finally, a choice must be made between which elements should be included in the agreement itself and what can be delegated to decision-making by the COP.

\section{Equity and Differentiation}

The success of the negotiations under the ADP will, among other things, also depend on a common understanding of equitable sharing of efforts. While equity is a principle of the Convention, its meaning and scope remain contentious. In general terms, equity refers to the quality of being impartial, fair and just. In the international climate discourse, equity and fairness are used interchangeably. ${ }^{26}$ The broad understanding is that the new agreement must reflect states' different “situations”, whether they are the stage of development, economic means, risk (exposure and vulnerability) of climate impacts, contributions to increasing GHG concentrations in the atmosphere - both historical, current and future trends - , technological capacities etc. States differ in many regards and these differences must be duly reflected in the architecture of the new agreement.

At the same time, the design of an equitable regime poses a paramount challenge to the traditional structure of public international law, which is based on the sovereign equality

\footnotetext{
${ }^{26}$ J Ashton and X Wang, 'Equity and Climate: In Principle and Practice' in J.E.Aldy, Beyond Kyoto, Advancing the international effort against climate change, Pew Center on Global Climate Change (2003), 62.
} 
of states. States are supposed to be treated equally, where as a starting point the same rights and duties apply to all. There is, however, growing understanding that in order to treat states equally, their differences must be taken into account. Differentiation and positive discrimination (e.g. trough affirmative action) is necessary in order to treat different states on an equal basis. Traditionally, international law is defined by the sovereign equality of states which guarantees that all states have equal rights and obligations. Since the 1972 Stockholm Conference, international environmental treaty-making has changed from providing identical treatment to all contracting states to providing for differential treatment of developing countries, based on concepts of co-operation and solidarity. The idea is to bring about effective - rather than formal - equality among de facto unequal states and to ensure the participation of all countries in international environmental agreements.

With the 1992 Rio Declaration a specific form of differential treatment has found its way into international environmental law-making. The Declaration’s Principle 7 reads:

"States shall cooperate in a spirit of global partnership to conserve, protect and restore the health and integrity of the Earth’s ecosystem. In view of different contributions to global environmental degradation, States have common but differentiated responsibilities. The developed countries acknowledge the responsibility they bear in the international pursuit of sustainable development in view of the pressures their societies place on the global environmental and of the technologies and financial resources they command.”

An equitable approach to the climate challenge is often understood as an approach based on the principle of common but differentiated responsibilities and respective 
capabilities (CBDRRC) as mentioned in Article 3 UNFCCC, which - different from the Rio Declaration - says that:

«...parties should act to protect the climate system "on the basis of equity and in accordance with their common but differentiated responsibilities and respective capabilities.”

This principle has so far mainly been used by major developing countries in the context of the Rio Declaration as an argument for demanding from developed countries to acknowledge their historic contributions to the increased concentration of greenhouse gases in the atmosphere and act accordingly by "taking the lead" in climate mitigation and finance. ${ }^{27}$ The other side of this argument is that developing countries - having historically contributed marginally to the current concentrations - should not be required to take on mandatory commitments to reduce their GHG emissions. The CBDRRC principle is reflected in the “firewall” between developed (Annex-I) and developing (non-Annex) countries and is the main reason for the current difficulties to finding a truly equitable solution.

Differentiation has so far been along the dividing line of "developed" and “developing” states and according to historical contributions of developed countries to environmental degradation, as well as developed countries capability to engage in costintensive environmental mitigation action. These factors (criteria) have led to substantively stronger obligations of developed countries, with developing countries having no or milder obligations as well as entitlements to financial transfers as well as transfer of technology and know-how from developed countries. Based on these criteria, "positive discrimination” in favour of developing countries has led to highly asymmetric environmental obligations

${ }^{27}$ Arts. 3, 4.2 and 4.7 UNFCCC. 
coupled with mechanisms for capacity building, transfer of financial resources and technology as well as compliance assistance.

The immense current global challenges all states commonly face can only be tackled by taking cooperative large-scale remedial action. However, the factual preconditions under which states are acting still differ considerably. Yet, the "landscape of similarities and differences” has changed since its perception more than 40 years ago. The world is characterized by disparities in resources and capabilities in different ways now. The antagonistic dividing line between developed and developing countries is becoming increasingly blurred. Any of the two groups, if they can be identified at all ${ }^{28}$, is no longer homogenous but marked by stark internal differences. In addition, the international landscape undergoes changes and fluctuations. Any attempt of categorization might be insufficient to capture such dynamism. For that reason, there need to be more differentiation ${ }^{29}$ and differentiation should be flexible and dynamic and only be granted on a temporary basis.

At the time of the conception of the Convention, this "grouping” of states might have been a suitable reflection of the state of the world. But 20 years on, it isn't. Not only have a number of developing countries become economies with strong growth, they also have increased and partly overtaken to highest emitting developed countries - and trends are

\footnotetext{
${ }^{28}$ See, for example, the classification by the International Monetary Fund (IMF) in "advanced economies" and "emerging market and developing economies". International Monetary Fund, World Economic Outlook, October 2012, p. 179. The IMF notes: "This classification is not based on strict criteria, economic or otherwise, and it has evolved over time.” p. 177. According to the United Nations Statistics Division,”There is no established convention for the designation of "developed" and "developing" countries or areas in the United Nations system." See: UNSD, Composition of macro geographical (continental) regions, geographical sub-regions, and selected economic and other groupings (fn. C), revised 11 October 2012, available at: http://unstats.un.org/unsd/methods/m49/m49regin.htm\#ftnc.

${ }^{29}$ See also Joost Pauwelyn, The End of Differential Treatment for Developing Countries? Lessons from the Trade and Climate Regimes, 22(1) RECIEL 2013, 29-41, who argues for more differentiation and further subdivisions.
} 
continuing. ${ }^{30}$ A differentiation of responsibility to address the climate challenge that rests entirely on history contributions is not only not fair - it is not effective. In short, it is dangerous, because it will miss out on those emissions that cause global temperatures to tilt towards 4 degrees or more. Moreover, the traditional binary differentiation does not address the heterogeneity that is found within the group of developing as well as developed countries. The question is thus how to reflect the different "situations" of states and their dynamic development in the new agreement. The change in the world between 1992 and 2013 tells us that such differentiation cannot be static; it needs to be based on dynamic and flexible parameters, which allow the structure of the agreement to evolve - as the world evolves.

When the ADP was adopted in Durban, the decision was free from references to developed/developing or Annex-I non-Annex countries. Such wording was celebrated as breaking down the traditional firewall between the two major groups. But already the ADP decision from Doha, December 2012, has Parties acknowledge that the ADP “shall be guided by the principles of the Convention”. ${ }^{31}$ While attempts to include explicitly the principle of common but differentiated responsibilities and respective capabilities or to refer to the climate paragraphs of the outcome document of Rio+20 were not successful, the principles of the convention are non-negotiable as guiding principles also for the ADP. ${ }^{32}$

The argument put forward in this chapter is, that the principles of the convention must apply, but they are not static. Their principled character is a means to adjust and adopt the convention to changing political circumstances. Principles of law provide a necessary means by which law can develop in a dynamic fashion that is responsive to today’s problems.

\footnotetext{
${ }^{30}$ See the overview over annual global carbon budgets and trends updated by the Global Carbon Budget, available at: http://www.globalcarbonproject.org/carbonbudget/index.htm

${ }^{31}$ Decision $\mathrm{x} / \mathrm{CP} .18$.

${ }^{32}$ Summary of the Roundtable Under Workstream 1, ADP1, part 2, Doha, Qatar, November-December 2012, Note by the Co-Chairs, 7 February 2013 (ADP.2012.6.InformalSummary), at page 2.
} 
Principles are 'an authoritative recognition of a dynamic element on international law ${ }^{33}$ Law is a continuing process and principles provide for a 'welcome possibility for growth' ${ }^{34}$, in which capacity they also contribute to the development of international law. Principles are never 'finished products'. It is a 'continuing process' from their identification to the final determination of the principles' content in a particular context. ${ }^{35}$

While so far, only one particular interpretation of the CBDRRC principle (i.e. differentiation based on historic contributions) has dominated the climate negotiations, the time has come for more countries to put forward their (evolved) understanding of that principle. In Doha, a number of countries came forward with their understanding that the CBDRRC principle is reflective of certain dynamism in the climate regime as it is not set in stone, but evolves over time. In the on-going ADP negotiations, many Parties therefore observed "that the principles [of the Convention] are not rigid, and should be applied in a dynamic and evolving manner taking into account national circumstances, changing economic realities and levels of development." 36 "Principles...need to be forward-looking and take into account what the world might look like in 2020.”37 Some Parties stated that also the application of the Convention "should be adapted in order to improve its vitality and relevance in the modern world and in order to enable it to become a modern instrument to address climate change. It was pointed out that the Convention has evolved, and will continue to evolve over time, and thus the manner in which the principles apply also needs to evolve."38

\footnotetext{
${ }^{33} \mathrm{~J}$ L Brierly, (H. Waldock ed.) The Law of Nations: An Introduction to the International Law on Peace (Oxford: Clarendon), 1963, 63.

${ }^{34}$ See M Bos, The Recognized Manifestations of International Law, 20 German Yearbook of International Law, 1977, 42.

${ }^{35}$ Bos, $1977,42$.

${ }^{36}$ Summary of the Roundtable under Workstream 1, ADP1, part 2, Doha, Qatar, November-December 2012, Note by the Co-Chairs, 7 February 2013 (ADP.2012.6.InformalSummary) at page 3.

${ }^{37}$ Ibid.

${ }^{38}$ Ibid.
} 
Yet, finding reliable, but flexible and dynamic, criteria or means to defining various (groups of) "equals” and allocating rights and responsibilities accordingly, may be an impossible task in multilateral environmental treaty making. Instead, alternatives to criteriabased differentiation should be explored. We suggest as such alternatives self-differentiation within a spectrum of options.

As a starting point, the question of how to treat differentially is different from the question of how to 'group' parties. Traditionally, differentiation has been made along the fault line of “developed” and “developing” countries. This antagonistic dividing line is increasingly blurred and particularly difficult to maintain in a climate context for some of the fastest growing developing countries. Differentiation should thus be flexible and dynamic and only be granted on a temporary basis.

In terms of giving flexibility to differentiations, the 1991 Volatile Organic Compounds (VOC) Protocol to the Convention on Long-Range Transboundary Air Pollution (LRTAP VOC Protocol) stands out as an interesting approach. It establishes specific targets and timetables which commit Parties to control and reduce their emissions of VOCs. In order, however, to reflect the need for differentiation based on a party’s emissions and particular geographic and demographic circumstances, the VOC Protocol offers Parties three ways to meet the emission reduction requirement. Upon signature or ratification, a Party must chose one of these options. While the first option is open to all Parties, the availability of the other two options depends on particular criteria and circumstances. 
The first option to achieve emission reductions is for (any) Party to "take effective measures to reduce its national annual emissions of VOC's by at least thirty per cent by the year 1999, using 1988 levels as a basis or any other annual level during the period 1984 to 1990, which it may specify upon signature of or accession to the present Protocol.”39

The second option is only available to a Party whose annual emissions contribute to tropospheric ozone concentrations in areas under the jurisdiction of one or more other parties, and where such emissions originate only from an area under its jurisdiction that is specified as tropospheric ozone management areas (TOMAs) under Annex I to the Protocol. ${ }^{40}$ A Party that chooses this way shall "as soon as possible and as a first step, take effective measures to: (i) Reduce its annual emissions of VOCs from the areas so specified by at least 30 per cent by the year 1999, using 1988 levels as a basis or any other annual level during the period 19841990, which it may specify upon signature of or accession to the present Protocol; and (ii) ensure that its total national annual emissions of VOCs by the year 1999 do not exceed the 1988 levels.” ${ }^{41}$

The third way is only available to Parties whose national annual emissions of VOCs were in 1988 lower than 500,000 tonnes and $20 \mathrm{~kg} /$ inhabitant and 5 tonnes $/ \mathrm{km}^{2}$. Such a Party "shall, as soon as possible and as a first step, take effective measures to ensure at least that at the latest by the year 1999 its national annual emissions of VOCs do not exceed the 1988 levels.» ${ }^{42}$

\footnotetext{
${ }^{39}$ Art. 2(2)(a) VOC Protocol. This option has been chosen by Austria, Belgium, Estonia, Finland, France, Germany, Netherlands, Portugal, Spain, Sweden and the United Kingdom with 1988 as base year, by Denmark with 1985, by Liechtenstein, Switzerland and the United States with 1984, and by Czech Republic, Italy, Luxembourg, Monaco and Slovakia with 1990 as base year).

${ }^{40}$ Art. 2(2)(b) VOC Protocol. Annex I specifies TOMAs in Norway (base year 1989) and Canada (base year 1988). The total Norwegian mainland as well as the exclusive economic zone south of $62^{\circ} \mathrm{N}$ latitude in the region of the Economic Commission for Europe (ECE), covering an area of 466,000 km2, is a TOMA.

${ }^{41}$ Art. 2(2)(b) VOC Protocol. This has been chosen by Bulgaria, Greece, and Hungary.

${ }^{42}$ Art. 2(2)(c) VOC Protocol.
} 
Furthermore, no later than two years after the protocol entered into force each party was required to apply appropriate (!) national or international emission standards to new stationary and new mobile sources based on "best available technologies which are economically feasible” (BATEF). No later than 5 years after the entry into force, in those areas in which national or international tropospheric ozone standards are exceeded or where transboundary fluxes originate or are expected to originate, each Party must apply BATEF to existing stationary sources in major categories. ${ }^{43}$

In carrying out their obligations, Parties are invited to give highest priority to reduction and control of emissions of the substances with the greatest photochemical ozone creation potential. Innovative is further the requirement that states must ensure that they do not substitute toxic and carcinogenic VOCs, and those that harm the stratospheric ozone layer, for other VOCs. ${ }^{44}$

The success of the LRTAR is partly due to its restricted regional scope and its comparatively small and homogenous group of Parties. It has nevertheless served as a model for the UNFCCC and the Vienna Convention on the Protection of the Ozone Layer.

One lesson from the VOC Protocol for the climate negotiations is that by giving Parties the (free) choice of option based on certain criteria for availability of that particular option - or no criteria - the Parties themselves can find their 'group' in some form of “selfdifferentiation”. As, for example, option three of the VOC Protocol illustrates, certain

\footnotetext{
${ }^{43}$ Art. 3 VOCs Protocol.

${ }^{44}$ Art. 5 VOC Protocol.
} 
emission intensity criteria (e.g. $\mathrm{t} /$ capita or $\mathrm{t} / \mathrm{km}^{2}$ ) or overall emission amounts or other economic, demographic and/or geographic criteria can be included in the design of options.

In addition, the options could differ either in substance (higher baselines or different base years or reference levels, higher emissions caps or less stringent targets) or in form (flexibility for implementation, supplementarity, time frame for implementation etc.) or in both. For example, some options might be equal in substance, but differ in the timeframe for implementation periods (so-called grace periods as in the Montreal Protocol). Moreover, some options could be linked to either providing or receiving financial, technology and scientific support and assistance. This could be fine-tuned with the particular design of the various options. One example could be the choice between two particular options, where one includes stronger emission reduction targets but weaker obligations to provide financial support, whereas the other option contains the opposite: more moderate emission reduction targets coupled with significant financial transfer obligations. Such an 'optioning' approach coupled with criteria for the availability of particular options by otherwise free choice could open for much needed flexibility in the design of new international environmental agreements, climate change in particular.

While the optioning-approach could be a feasible way forward it is important to keep the architecture dynamic. Dynamic elements should thus be integrated into the options or complement them (see VOC Protocol, Art. 3). Dynamic elements in terms of technological responses are, for example, the requirement of using "best available technologies” or "best practices”. Dynamism in terms of substance can also be maintained by (i) adopting a "critical loads” approach which allow for upward adjustments (ii) regular review of the appropriateness of the targets in the light of latest scientific findings, (iii) by automatic 
strengthening of commitments in given intervals, adjustments on the basis of available scientific, environmental, technical and economic information (see art. 6 Montreal Protocol) (iv) or by review of the level of ambition by an assessment expert panel.

The point is that there will not be one type of differentiation that "fits all” and covers all the very different circumstances and situations in country Parties. It will be the right combination or “mix" of substantive commitments, incentive structures, entitlements, procedural requirements etc. which will be crucial for the success of a new agreement. A well-designed and fine-tune “catalogue” of options (with differing commitments and/or entitlements) which Parties can chose from upon signature or ratification might be a feasible way forward, reflecting the diversities of a globalized and interconnected world in the sophisticated design of a comprehensive agreement.

\section{Conclusions}

The negotiations of the new climate agreement face challenges both regarding its legal form and its principles. The Durban Platform establishes a framework by the requirement that the agreement shall be 'a protocol, another legal instrument or an agreed outcome with legal force under the Convention applicable to all parties'. While the formulation is marked by 'constructive ambiguity', it provides guidance and allows states to choose between the distinctive options of adopting a new protocol, amendments to the UNFCCC (or annexes or amendments to annexes), or a package including delegation of powers to the COP to adopt legally binding decisions. 
But the future climate agreement raises also the question about the legally binding character of each of its elements. This should be decided on the basis of the international legal consequences of choosing a legally binding form of the relevant element, i.e. a functional approach. It would generally seem that the stringency and complexity required of a new agreement would militate in favour of legally binding elements. However, the need for a dynamic regime suggests that extensive decision-making power should be delegated to the COP.

It is also necessary to rethink the relationship between the sovereign equality of states and the meaning of equity in light of the principle of common but differentiated responsibilities and respective capabilities (CBDRRC). The UNFCCC and the Kyoto Protocol make a sharp distinction between Annex I and non-Annex I states. But the economy of and emissions from different states have become so heterogeneous that it is no longer desirable to uphold this binary character of states. There is a need for more differentiation, flexibility and dynamism. This could include the possibility that states choose between different options of substantive commitments (“self-differentiation”), incentive structures, etc., combined with dynamic criteria, such as using "best available technology”, or a “critical loads” approach which allows for upward adjustment of commitments.

Such an approach would be less prescriptive than a (unrealistic) top-down structure but more ambitious than mere bottom-up approaches, while leaving necessary freedom and flexibility to the Parties. 
J Ashton and X Wang, 'Equity and Climate: In Principle and Practice’, in J.E. Aldy et al. (eds.), Beyond Kyoto, Advancing the international effort against climate change (Pew Center on Global Climate Change, 2003)D Bodansky, 'The United Nations Framework Convention on Climate Change: A Commentary' 199318 Yale Journal of International Law 451-558 D Bodansky, The Art and Craft of International Environmental Law (Cambridge, Mass., Harvard University Press,2010)

D Bodansky, The Durban Platform Negotiations: Goal and Options, Harvard Project on Climate Agreements, Viewpoint, June 2012, 3 D Bodansky, The Durban Platform: Issues and Options for a 2015 Agreement (Center for Climate and Energy Solutions. Available at

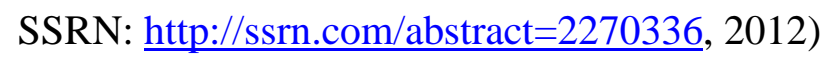

ICJ, Whaling in the Antarctic (Australia V. Japan) Application (2010)

M Bos, The Recognized Manifestations of International Law, 20 German Yearbook of International Law, 1977, 42

J L Brierly, (H. Waldock ed.) The Law of Nations: An Introduction to the International Law on Peace (Oxford: Clarendon), 1963, 63

J Pauwelyn, The End of Differential Treatment for Developing Countries? Lessons from the Trade and Climate Regimes, 22(1) RECIEL (2013), 29-41,

L Rajamani, 'Developing Countries and Compliance in the Climate Regime' in J Brunnée and others (eds), Promoting Compliance in an Evolving Climate Regime (CUP, 2012) 367-395 L Rajamani, The Durban platform for enhanced action and the future of the climate regime, 61:2 International Comparative Law Quarterly, 2012, 506.

G Ulfstein and J Werksman, 'The Kyoto Compliance System: Towards Hard Enforcement' in OS Stokke and others (eds), Implementing the Climate Regime. International Compliance (Earthscan, London Sterling, VA 2005) 
C Voigt, The Legal Form of the Durban Platform Agreement: Seven Reasons for a Protocol, 15:3 Ethics, Policy \& Environment (2012) 276-282

J Werksman, 'Compliance and the Use of Trade Measures' in J Brunnée and others (eds), Promoting Compliance in an Evolving Climate Regime (CUP, 2012) 262-286

J Werksman, Q\&A: The Legal Aspects of the Durban Platform Text, WRI Insights, 14 December, 2011. 